ORIGINAL PROF-2084

\title{
PERIPHERAL ARTERIAL DISEASE (PAD);
}

Frequency in diabetics.

Dr. Qaiser Mahmood, Dr. Nasreen Siddique, Dr. Affan Qaiser

ABSTRACT... Objectives: (1) To determine the frequency of PAD in diabetic patients. (2) To compare the frequency of PAD in diabetics taking different treatment modalities. Design: Observational Cross-sectional study. Setting: Diabetic Research Centre Nishtar Hospital Multan. Period: Dec. 2010 to Dec.2011. Material and method: Four hundred and forty three (443) consecutive diabetic patients were included in the study .History, Clinical Examination, Blood Sampling, HBA1C and Doppler's studies for ABI were carried out. Grading of severity of PAD was done on the basis of ABI. Results: A total of 443 diabetic patients were screened for PAD by ABI. Out of 443 diabetic patients 346(78.1\%) were males and $97(21.9 \%)$ were females. 332(74.9\%) patients were in age group 35-45 years, having normal ABI. $111(25.1 \%)$ patients were in age group of $45-55$ years having abnormal ABI. So on the basis of ABI the frequency of PAD was found 25.1\%. Among 111 diabetic patients with abnormal ABI 97(87.4\%) have mild to moderate PAD while 14(12.6\%) have severe PAD. Patients with severe PAD were in age group 55 and above and they have longer duration of diabetes. Out of 111 diabetic patients with abnormal ABI $87(78.4 \%)$ were males and $24(21.6 \%)$ were females indicating disease predominance in males. PAD was more common in patients who were on Oral hypoglycemic agents Conclusions: The study demonstrates a high prevalence of PAD among people with type 2 diabetes mellitus. This needs to be appropriately evaluated by the medical professionals.

Key words: Peripheral Arterial Disease, Ankle Brachial Index.

\section{Article Citation}

Mahmood Q, Siddique N, Qaiser A. Peripheral arterial disease (PAD); frequency in diabetics. Professional Med J 2013;20(4): 513518.

\section{INTRODUCTION}

PAD is a slow progressive atherosclerotic occlusive disorder of arterial system and may involve any blood vessel but legs and feet are most commonly affected, thus the name PAD. It is commonly manifested as intermittent claudication or critical limb ischaemia ${ }^{1}$.

It is twice common among diabetics compared with non-diabetics and is strong predictor of subsequent cardiovascular morbidity \& mortality in patients with type 2 diabetes ${ }^{2}$.

American Heart Association (AHA) estimates that 810 million Americans have PAD, Nearly $70-80 \%$ affected individual are asymptomatic, Over a 5 years period $25-35 \%$ people with PAD will suffer myocardial infarction (MI) or stroke and an additional $25 \%$ will die, usually from cardiovascular cause within 6 months ${ }^{3}$.

It has been reported that patients with PAD and diabetes experience worse lower-extremity dysfunction than those with PAD alone ${ }^{4}$, but only minority require revascularization and amputation ${ }^{5}$.

Diabetes mellitus is especially considered as an important risk factor for $\mathrm{PAD}^{6}$.

Other risk factors are smoking, advanced age, hypertension, obesity, hyperlipidemia, Male, Post menopausal female, hyperhomocysteinemia and physical inactivity?

The number of diabetics is increasing in Pakistan as a result of urbanization, physical inactivity and obesity. Pakistan is considered to be one of the countries with the largest population of people with diabetes and is ranked seventh globally by the International Diabetes Foundation $^{8}$.

The prevalence of diabetes is high in Pakistan ranging from $7.6 \%$ to $11 \%$ among adults ${ }^{9}$. The incidence of symptomatic PAD increases with age from about $0.3 \%$ 
/ year for men aged 40-55years to about $01 \%$ /year for men aged over $75 y$ years ${ }^{10}$.

In USA the prevalence of PAD is $12-20 \%$ after the age of 65 years and prevalence of PAD also increases with the duration of $\mathrm{DM}^{11}$.

It is important to diagnose diabetes early and offer treatment to avoid PAD and other vascular complications $^{12}$. For early diagnosis the inter digital spaces should also be inspected for fissures, ulcerations, and infections in addition to other investigations ${ }^{13}$.

Ankle Brachial Index (ABI), which is the ratio of ankle to brachial systolic blood pressure, is $95 \%$ sensitive and $100 \%$ specific, a simple, non-invasive and reliable bedside method for diagnosing the presence and severity of $P A D^{14}$.

American College of Cardiology / American Heart Association (ACC/AHA) recommend measurement of $A B I$ in symptomatic patients as a diagnostic criterion ${ }^{15}$.

A patient with an $A B I$ of $<0.9$ was classified as having $P A D$, as many studies have found that a ratio of $\leqslant 0.90$ signifies the presence of $P A D^{16}$. The recently published U.K prospective Diabetes study has shown that intensive glucose control reduces effectively microvascular complications in patients with type 2 Diabetes $^{17}$.

\section{PURPOSE OF STUDY}

The purpose of study was intended to determine the frequency of PAD in diabetic patients. Diabetes mellitus is especially considered as an important risk factor for PAD and the number of diabetics is increasing in Pakistan as a result of urbanization, physical inactivity and obesity. Ankle Brachial Index $(A B I)$, is a simple, non-invasive and reliable bedside method and was used for diagnosing the presence and severity of PAD.
The other purpose of study was to compare the frequency of PAD in diabetics taking different treatmentmodalities.

\section{MATERIAL AND METHODS}

It was a hospital based observational Cross-sectional study carried out at Diabetic Research Centre Nishtar Hospital Multan during the period from Dec. 2010 to Dec.2011.

Four hundred and forty three (443) consecutive diabetic patients were included in the study. History, Clinical Examination, Blood Sampling, HBA1C and Doppler's studies for $A B I$ were carried out. Ankle Brachial Index (ABI), which is the ratio of ankle to brachial systolic blood pressure, was used for grading of severity of PAD. A patient with an ABI of $<0.9$ was classified as having PAD.

\section{RESULTS}

A total of 443 diabetic patients were screened for PDA by $A B I$.

Out of 443 diabetic patients $346(78.1 \%)$ were males and $97(21.9 \%)$ were females. Table-l.

\begin{tabular}{|l|c|c|}
\hline & No. of cases & \%age \\
\hline Male & 346 & 78.1 \\
\hline Female & 97 & 21.9 \\
\hline Total & 443 & 100 \\
& \multicolumn{2}{|c|}{ Table-I. Sex distribution } \\
\end{tabular}

$332(74.9 \%)$ patients were in age group 35-45 years, having normal $A B I .111(25.1 \%)$ patients were in age group of $45-55$ years having abnormal $A B I$. So on the basis of $A B I$ the frequency of PAD was found $25.1 \%$. Table-ll.

Out of 111 diabetic patients with abnormal $A B I$ $87(78.4 \%)$ were males and $24(21.6 \%)$ were females indicating disease predominance in males. Table-III. $97(87.4 \%)$ have mild to moderate PAD while 


\begin{tabular}{|l|c|c|}
\hline \multicolumn{1}{|c|}{ AB } & No. of cases & \%age \\
\hline Normal $>0.9$ & 332 & 74.9 \\
\hline Abnormal $<0.9$ & 111 & 25.1 \\
\hline Total & 443 & 100 \\
\hline \multicolumn{2}{|c|}{ Table-II. Frequency distribution of PAD on the basis of ABI } \\
$(\mathrm{n}=443)$
\end{tabular}

\begin{tabular}{|l|c|c|}
\hline \multicolumn{1}{|c|}{ Sex } & No. of cases & \%age \\
\hline Male & 87 & 78.4 \\
\hline Female & 24 & 21.6 \\
\hline Total & 111 & 100 \\
\multicolumn{2}{|c|}{ Table-III. Sex distribution of PAD on basis of ABI $(n=111)$} \\
\hline
\end{tabular}
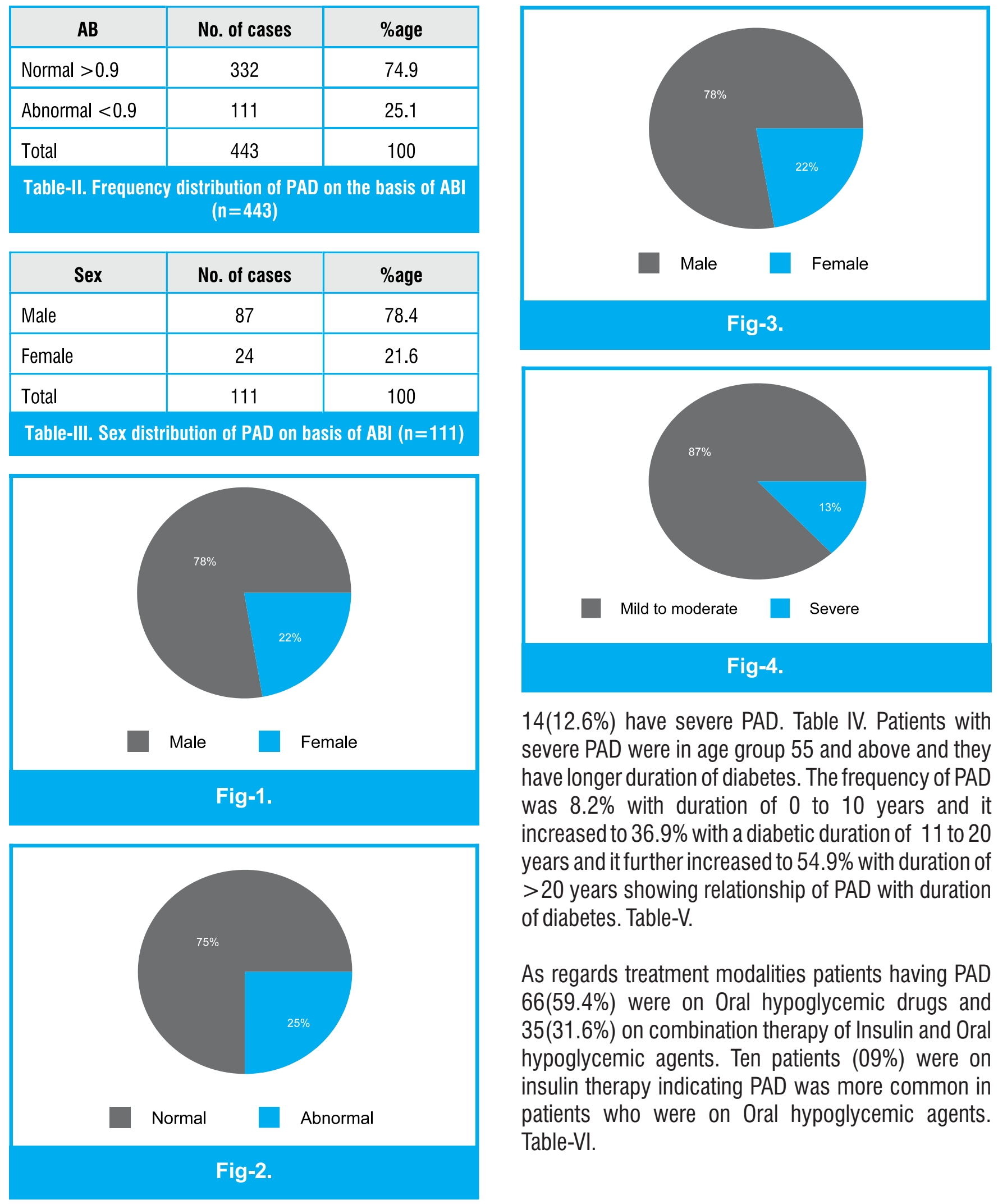

14(12.6\%) have severe PAD. Table IV. Patients with severe PAD were in age group 55 and above and they have longer duration of diabetes. The frequency of PAD was $8.2 \%$ with duration of 0 to 10 years and it increased to $36.9 \%$ with a diabetic duration of 11 to 20 years and it further increased to $54.9 \%$ with duration of $>20$ years showing relationship of PAD with duration of diabetes. Table-V.

As regards treatment modalities patients having PAD $66(59.4 \%)$ were on Oral hypoglycemic drugs and $35(31.6 \%)$ on combination therapy of Insulin and Oral hypoglycemic agents. Ten patients (09\%) were on insulin therapy indicating PAD was more common in patients who were on Oral hypoglycemic agents. Table-VI. 


\begin{tabular}{|l|c|c|c|c|}
\hline $\begin{array}{c}\text { Severity of } \\
\text { PDA }\end{array}$ & ABI & $\begin{array}{c}\text { No. of } \\
\text { cases }\end{array}$ & $\begin{array}{c}\text { Age in } \\
\text { years }\end{array}$ & \%age \\
\hline $\begin{array}{l}\text { Mild to } \\
\text { moderate }\end{array}$ & $\begin{array}{c}0.41- \\
0.90\end{array}$ & 97 & $45-55$ & 87.4 \\
\hline Severe & $0.00-0.4$ & 14 & $>55$ & 12.6 \\
\hline Total & - & 111 & - & 100 \\
\hline \multicolumn{4}{|c|}{ Table-IV. Severity of PAD on basis of ABI and age } \\
$(\mathrm{n}=111)$
\end{tabular}

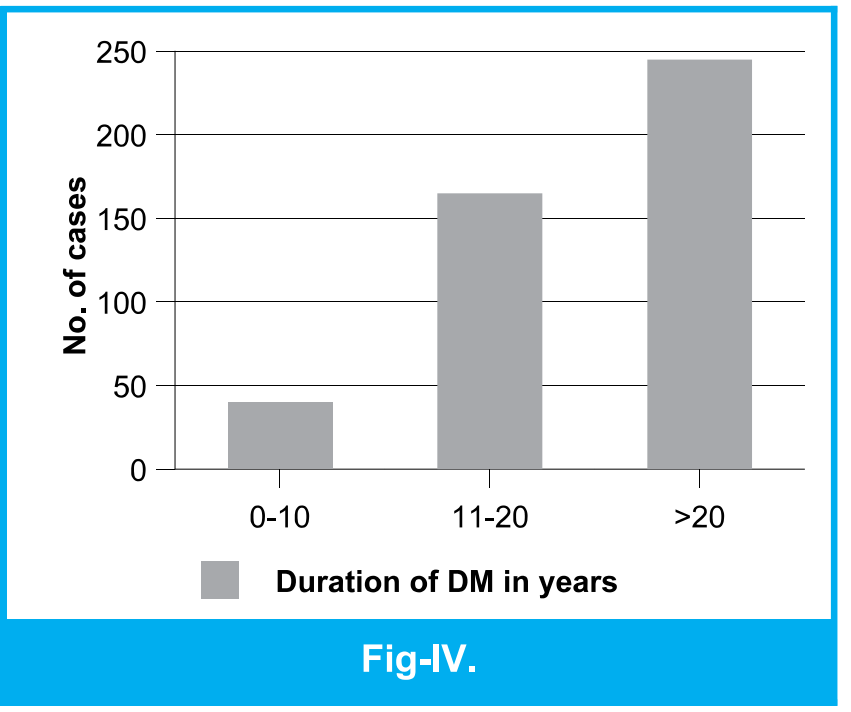

\begin{tabular}{|l|c|c|}
\hline \multicolumn{1}{|c|}{ Duration of DM (years) } & No. of cases & \%age \\
\hline $0-10$ & 09 & 8.2 \\
\hline $11-20$ & 41 & 36.9 \\
\hline$>20$ & 61 & 54.9 \\
\hline Total & 111 & 100 \\
\hline
\end{tabular}

\section{DISCUSSION}

Various studies have shown that chronic hyperglycemia is an established risk factor for PAD. It has been hypothesized that $10 \%$ to $20 \%$ of persons with type 2 diabetes mellitus have $P A D^{18}$.

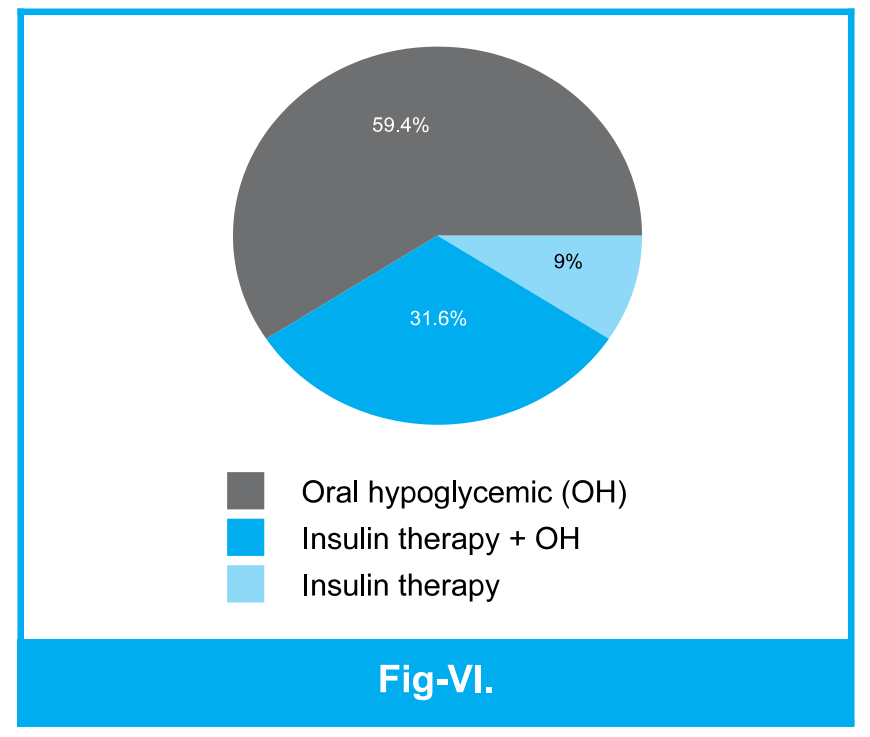

\begin{tabular}{|l|c|c|}
\hline \multicolumn{1}{|c|}{ Treatment modalities } & No. of cases & \%age \\
\hline $\begin{array}{l}\text { Oral hypoglycemic agents } \\
\text { (OHA) }\end{array}$ & 66 & 59.4 \\
\hline Insulin therapy + OHA & 35 & 31.6 \\
\hline Insulin therapy & 10 & 9.0 \\
\hline Total & 111 & 100 \\
\hline \multicolumn{2}{|c|}{ Table-VI. Frequency of PAD on the basis of } \\
treatment modalities
\end{tabular}

In our study the frequency of PAD was 25\%.

A large number of epidemiological and clinical studies have pointed the association of PAD incidence with patient age, sex and duration of diabetes.

In one of the study consecutive 100 patients were screened, prevalence of PAD was $8 \%$. Nearly 60 patient (60\% were over the age of 50 years) male predominance was $70 \%$.

In our study also Out of 111 diabetic patients with abnormal $\mathrm{ABI} 87(78.4 \%)$ were males and $24(21.6 \%)$ were females indicating disease predominance in males. 
The incidence of symptomatic PAD increases with age from about $0.3 \%$ / year for men aged 40-55years to about $01 \% /$ year for men aged over $75 y$ ears ${ }^{10}$.

The prevalence of PAD also increases with the duration of diabetes mellitus. The prevalence of PAD was 5.3\% with duration of 0 to 10 years. The prevalence of PAD increase to $42.9 \%$ with a diabetic duration of between 11 to 20 years and it increase to $50 \%$ if the duration was 21-30 years ${ }^{11}$.

In our study the frequency of PAD is $8.2 \%$ with duration of 0 to 10 years and it increases to $36.9 \%$ with a diabetic duration of 11 to 20 years and it further increase to $54.9 \%$ with duration of $>20$ years.

The severity of the PAD in clinical picture has been standardized according to the ankle brachial index $(A B I)$ values into four stages:

asymptomatic stage(ABI 0.80 to 0.95 ), intermittent claudication ( $A B I 0.5$ to 0.8 ), chronic critical ischemia (ABI 0.3 to 0.5$)$, and foot necrosis/gangrene ( $A B I \leqslant$ $0.2)^{19}$.

In our study among 111 diabetic patients with abnormal $A B I$ 97(87.4\%) have mild-moderate PAD while $14(12.6 \%)$ have severe PAD.

A cross-sectional study performed by Walters et al found an $8.7 \%$ prevalence of PAD among patients who were on insulin therapy and $23.5 \%$ among patients who were on oral hypoglycaemic agents ${ }^{20}$. In our study also frequency of PAD was more in patients who were on oral hypoglycaemic agents.

\section{CONCLUSIONS}

The study demonstrates a high prevalence of PAD among people with type 2 diabetes which needs to be appropriately evaluated by the medical professionals. Measurement of $\mathrm{ABI}$, correlates with the clinical condition, is a simple and effective method for diagnosing the disease early which can help in reducing the risk of complications associated with PAD.

\section{RECOMMENDATIONS}

Good glycemic control, early screening \& diagnosis of PAD could be a barrier to prevent further $C V$ risk.

\section{Copyright@ 10 Nov, 2012.}

\section{REFERENCES}

1. American Diabetes Association. Peripheral arterial disease in people with diabetes. Diabetes Care 2003; 26: 3333-41.

2. Glycaemic control in acute coronary syndromes: prognostic values and therapeutic options. European Heart Journal July1,201031:1557-1564.

3. McDaniel MD, Cronenwett JL: Basic data related to the natural history of intermittent claudication. Ann Vasc Surg 3:273-277, 1989.

4. Beckman JA, Creager MA, Libby P: Diabetes and atherosclerosis: epidemiology, pathophysiology, and management. JAMA 287:2570-2581, 2002.

5. Dolan NC, Liu K, Criqui MH, Greenland P, Guralnik JM, Chan C, Schneider JR, Mandapat AL, Martin G, McDermott MM: Peripheral artery disease, diabetes, and reduced lower extremity functioning. Diabetes Care 25:113-120, 2002.

6. White C. Intermittent claudication. N Engl J Med 2007; 356: $1241-50$.

7. Elhadd TA, Robb R, Jung RT, Stonebridge PA, Belch JJF: Pilot study of prevalence of asymptomatic peripheral arterial occlusive disease in patients with diabetes attending a hospital clinic. Practical Diabetes Int16:163-166, 1999

8. International Diabetes Federation. IDF Diabetes Atlas, 4th ed. [Internet]. Brussels, Belgium: International Diabetes Federation, 2009. (Online) (Cited $2010 \mathrm{Dec}$ 29). Available from URL: http://www.diabetesatlas. com/content/prevalence-estimates-diabetes-mellitusdm-2010. 
9. Hakeem R, Fawwad A. Diabetes in Pakistan: Epidemiology, determinants and prevention. Journal of Diabetology 2010; 3: 4 .

10. Coce $F$, Jaksiae B, Faktoria rizika dijabetieke obliterativne angiopatije. Diabetol Croat 1982;2:33740.

11. Orchard TJ,Dorman JS,Maser RE,et al. Prevalence of complications in IDMM by sex and duration. Pittsburg Epidemiology of Diabetes Complications study II Diabetes 1990;39:1116-24.

12. Newman AB, Shemanski L, Manolio TA, Cushman M, Mittelmark M, Polak JF, et al. Ankle-arm index as a predictor of cardiovascular disease and mortality in the cardiovascular health study. The Cardiovascular Health Study Group. Arterioscler Thromb Vasc Biol 1999; 19: 538-45

13. American Diabetes Association: Preventive foot care in people with diabetes (Position Statement). Diabetes Care 26 (Suppl. 1):S78-S79,2003.

14. American Diabetes Association. Peripheral arterial disease in people with diabetes. Diabetes Care 2003; 26: 3333-41.

15. Hirsch AT, Criqui MH, Treat-Jacobson D, Regensteiner JG, Creager MA, Olin JW, Krook SH, Hunninghake DB,
Comerota AJ, Walsh ME, McDermott MM, Hiatt WR Peripheral arterial disease detection, awareness, and treatment in primarycare. JAMA 286: 1317-1324, 2001.

16. Hooi JD, Stoffers HE, Kester AD, et al. Risk factors and cardiovascular diseases associated with asymptomatic peripheral arterial disease. The Limburg PAOD study. Peripheral Arterial Occlusive Disease. Scand J Prim Health Care 1998; 16: 177-82.

17. Clinical implications of ACCORD TRIAL. Journal of clinical endocrinology and Metabolism January1,2012 97:41-48.

18. Colwell J. Pharmacological strategies to prevent macrovascular disease in NIDDM Diabetes1997;46 (Suppl2):S131-S134.

19. Gibbons GW. Vascular surgery. In: Bakker K,Nieuwenhuijezen Kreuseman AC, eds. The Diabetic Foot: Proceedings of the First International Symposium on the Diabetic Foot. Amsterdam: Excerpta Medica; 1991. pp. 117-24.

20. Walters DP, Gatling W, Mullee MA, Hill RD. The prevalence, detection, and epidemiological correlates of peripheral vascular disease: a comparison of diabetic and non-diabetic subjects in an English community. Diabet Med 1992; 9:710-5.

\section{AUTHOR(S):}

1. DR. QAISER MAHMOOD

Assistant Professor of Medicine,

BVH, Bahawalpur.

2. DR. NASREEN SIDDIQUE

Associate Prof. / HOD Community Medicine

Nishtar Medical College, Multan.

3. DR. AFFAN QAISER

House Officer

Nishtar Hospital, Multan.
CORRESPONDENCE ADDRESS:

Dr. Nasrin Siddique

4-C, Nishtar Estate,

Nishtar Hospital,Multan.

dr.nasrin.qaiser@gmail.com 